\title{
Effect of Erythrina velutina and Erythrina mulungu in rats submitted to animal models of anxiety and depression
}

M.D. Ribeiro ${ }^{1}$,

G.M. Onusic ${ }^{1}$,

S.C. Poltronieri ${ }^{1}$ and M.B. Viana ${ }^{2}$

\author{
${ }^{1}$ Laboratório de Psicofarmacologia, Departamento de Psicologia e Educação, \\ Faculdade de Filosofia, Ciências e Letras de Ribeirão Preto, \\ Universidade de São Paulo, Ribeirão Preto, SP, Brasil \\ ${ }^{2}$ Departamento de Psicologia do Desenvolvimento, Faculdade de Psicologia, \\ Pontifícia Universidade Católica, São Paulo, SP, Brasil
}

\section{Correspondence}

M.B. Viana

Departamento de Psicologia do

Desenvolvimento

Faculdade de Psicologia, PUC

Rua Monte Alegre, 984

05014-901 São Paulo, SP, Brasil

Fax: +55-11-3868-3203

E-mail: mviana@pucsp.br

M.D. Ribeiro was the recipient

of a scholarship from CAPES.

G.M. Onusic and S.C. Poltronieri

are recipients of scholarships

from CNPq. M.B. Viana was the

recipient of a Research Grant

from FAPESP (No. 2002/14174-6).

Received May 19, 2005

Accepted November 10, 2005

\begin{abstract}
Erythrina velutina (EV) and Erythrina mulungu (EM), popularly used in Brazil as tranquilizing agents, were studied. The effects of acute and chronic oral treatment with a water:alcohol extract of EV (7:3, plant grounded stem bark; acute $=100,200,400 \mathrm{mg} / \mathrm{kg}$; chronic $=50,100$, $200 \mathrm{mg} / \mathrm{kg})$ were evaluated in rats $(\mathrm{N}=11-12)$ submitted to the elevated T-maze (for avoidance and escape measurements) model of anxiety. This model was selected for its presumed capacity to elicit specific subtypes of anxiety disorders recognized in clinical practice: avoidance has been related to generalized anxiety and escape to panic. Additionally, animals were treated with the same doses of EV and EM (water:alcohol 7:3, inflorescence extract) and submitted to the forced swim test for the evaluation of antidepressant activity $(\mathrm{N}=7-10)$. Both treatment regimens with EV impaired elevated T-maze avoidance latencies, without altering escape, in a way similar to the reference drug diazepam (avoidance 1, mean \pm SEM, acute study: $131.1 \pm 45.5$ (control), $9.0 \pm 3.3$ (diazepam), $12.7 \pm 2.9(200 \mathrm{mg} / \mathrm{kg}$ ), $28.8 \pm 15.3$ ( $400 \mathrm{mg} / \mathrm{kg}$ ); chronic study: $131.7 \pm 46.9$ (control), $35.8 \pm 29.7$ (diazepam), $24.4 \pm 10.4(50 \mathrm{mg} / \mathrm{kg}), 29.7 \pm 11.5(200 \mathrm{mg} / \mathrm{kg})$ ). Neither EV nor EM altered measurements performed in the forced swim test, in contrast to the reference drug imipramine that significantly decreased immobility time after chronic treatment. These results were not due to motor alterations since no significant effects were detected in an open field. These observations suggest that EV exerts anxiolytic-like effects on a specific subset of defensive behaviors which have been associated with generalized anxiety disorder.
\end{abstract}

Key words - Erythrina velutina

- Erythrina mulungu

- Elevated T-maze test

- Forced swim test

- Anxiety

- Depression

\section{Introduction}

At least 110 species of the genus Erythrina have been identified (1) and many of them are native to the American continent (2).
Erythrina plants produce alkaloids, flavonoids and terpenes $(3,4)$ and are also commonly used in folk medicine due to their tranquilizing effects (5). In fact, Erythrina americana has been shown to possess anti- 
convulsant, hypnotic, and analgesic activities (6) and, its alkaloids were shown to diminish aggressive behavior in a way similar to the benzodiazepine (BZD) diazepam (DZP), used as a control (5).

The designation Erythrina also includes the species Erythrina velutina (EV), endemic to the semi-arid regions of Northeastern Brazil, and Erythrina mulungu (EM), a plant native to Southern Brazil. In herbal medicine, EM is used to calm agitation and for insomnia and other disorders of the nervous system. In previous studies from our laboratory $(7,8)$, the effects of acute and chronic treatment with a water-alcohol extract of the inflorescence of EM were investigated in rats submitted to models specifically related to different types of anxiety disorder: the elevated T-maze (ETM, for inhibitory avoidance and one-way escape measurements), the light/dark transition, and the cat odor tests. Acute treatment with EM altered both inhibitory avoidance latencies in the ETM and the behavior of rats in the light/dark transition model, in a way similar to DZP. Since these two anxiety-related responses have been shown to be sensitive not only to low doses of BZD but also to the serotonin (5-HT) 1A agonist, buspirone, in terms of psychopathology they have been related to generalized anxiety, a clinical condition which responds to treatment with these pharmacological compounds. In contrast to DZP, however, chronic EM also altered ETM oneway escape, a task which has been related to panic disorder. This effect, which was similar to that observed with some antidepressant drugs in the model, i.e., imipramine and fluoxetine $(9,10)$, also used in clinical settings to treat panic disorder, suggests that chronically administered EM might possess both anxiolytic and panicolytic-like activity.

Recently, the anxiolytic potential of EV has been evaluated with animal models of anxiety. Thus, Vasconcelos and co-workers (11) studied the effects of hydroalcoholic extracts of both EV and EM on the behavior of female mice submitted to the open-field test and to the elevated plus-maze after oral ( $p o$ ) or intraperitoneal (ip) administration. The highest doses $(800 \mathrm{mg} / \mathrm{kg}$, po, and 400 $\mathrm{mg} / \mathrm{kg}$, ip) of the hydroalcoholic extracts decreased locomotor activity both in the open-field and in the elevated plus-maze test. The authors concluded that these results supported, at least in part, the popular use of the two species of Erythrina as tranquilizers in Brazilian folk medicine. Another study (12) performed with ip administration of an aqueous EV extract showed that the extract prolonged the duration of sleep induced by sodium pentobarbital at higher doses and blocked the acquisition of foot shock memory at lower doses. These results led the authors to propose that $\mathrm{EV}$ might interfere with the mnemonic process and might have a sedative action (12).

On the basis of these considerations, the purpose of the present study was to extend the evaluation of the potential therapeutic activity of both EV and EM. Thus, in a first experiment rats were orally treated with a hydroalcoholic EV extract and, after acute (100, 200, and 400 $\mathrm{mg} / \mathrm{kg}$ ) or chronic administration (21 days; 50,100 , and $200 \mathrm{mg} / \mathrm{kg}$ ), they were submitted to the ETM for the measurement of inhibitory avoidance and one-way escape responses. Since the anxiolytic potential of the plant was under investigation, DZP $(10 \mathrm{mg} / \mathrm{kg})$ was used as the reference drug. On the basis of previous observations performed with EM (8) and of a possible relationship between the pharmacological profile of the plant and that of the antidepressant compounds imipramine and fluoxetine, in a second part of the study, the effects of both EV and EM (same doses as before) were also investigated in the forced swim test (FST). In this case, imipramine (20 $\mathrm{mg} / \mathrm{kg}$ ) was used as the reference drug. The doses of EV and EM chosen were based on a pilot study performed with the elevated $\mathrm{T}$ maze in our laboratory. These doses were lower than those used by Vasconcelos and coworkers (11) to prevent impairment of loco- 
motor activity. However, in order to avoid confounding results due to treatment effects on locomotion, animals were also tested in an open field.

\section{Material and Methods}

\section{Animals}

Male Wistar rats (approximately 250$300 \mathrm{~g}$ in weight on the day of the tests) from the animal house of the University of São Paulo, Ribeirão Preto, SP, Brazil, were housed 5 or 6 to a cage until the experiments with the ETM or FST. Room temperature was controlled $\left(23 \pm 1^{\circ} \mathrm{C}\right)$ and lights were on from 7:00 to 19:00. Food and water were available ad libitum. The experimental procedures were in compliance with the US National Institutes of Health Guide for Care and Use of Laboratory Animals.

\section{Extract preparation}

Stem bark from EV was collected in the town of Pacoti, State of Ceará, Brazil, and the inflorescence from EM was collected in Rifaina, State of São Paulo, Brazil. Voucher EV specimens were deposited in the Prisco Bezerra Herbarium of the Federal University of Ceará under the number 16046. An EM exsiccate was deposited in the Department of Plant Biotechnology of the University of Ribeirão Preto under the code HPM0032. For the preparation of the hydroalcoholic extracts, $300 \mathrm{~g}$ of grounded EV stem bark and fresh EM inflorescence were extracted with $70 \%$ water and $30 \%$ ethanol. The crude extracts were then filtered and heated $\left(40^{\circ} \mathrm{C}\right)$ until reduction to $50 \%$ of their original volume by evaporation. The liquid obtained was frozen and subsequently lyophilized to give a dry residue $(5 \mathrm{~g})$.

\section{Compound administration}

For experiment 1, EV and DZP (Sigma, St.
Louis, MO, USA) were suspended in distilled water with $2 \%$ Tween 80 . For experiment 2 , EV, EM, and imipramine (Sigma) were suspended in distilled water. All solutions were prepared on the day of the experiment and administered $p o$ in a volume of $1 \mathrm{~mL} / \mathrm{kg}$.

\section{Apparatus}

Elevated T-maze test. The apparatus was made of wood and had three arms of equal dimensions $(50 \times 12 \mathrm{~cm})$. One arm was enclosed by $40-\mathrm{cm}$ high walls and was arranged perpendicularly to the two opposite open arms. The entire apparatus was elevated $50 \mathrm{~cm}$ above the floor. To prevent falls, the open arms were surrounded by a Plexiglas rim $1 \mathrm{~cm}$ high.

Forced swim test. Animals were forced to swim in a plastic cylinder $(30 \mathrm{~cm}$ in diameter by $40 \mathrm{~cm}$ in height) containing 25 $\mathrm{cm}$ of water at $21 \pm 1^{\circ} \mathrm{C}$. The water was changed after each subject was tested.

Open field. The apparatus used to measure locomotion was a wooden square box, $60 \times 60 \mathrm{~cm}$ with $30-\mathrm{cm}$ high walls. Its floor was divided into nine smaller squares of equal dimensions $(20 \times 20 \mathrm{~cm})$.

Luminosity at the level of the maze arms, the forced swim apparatus or at the center of the open field was 60 lux. For all experimental sessions, the behavior of the animals was recorded with a videocamera connected to a VHS recorder, for later analysis. During the analysis, the experimenter did not know which treatment each animal had received.

\section{Procedure}

\section{Experiment 1 - elevated T-maze}

Acute study. Three days after arrival in the laboratory, the animals were handled gently by the experimenter for $5 \mathrm{~min}$ for 2 consecutive days. On the 5th day, they were submitted to a 30-min forced exposure to one of the open arms of the maze one day 
before the test. It has been proposed that preexposure decreases the latency to leave this arm in a later trial, assuring that during escape measurements the animals are really escaping from aversion and not simply ambling (9). Twenty-four hours later, animals were randomly allocated to different treatment groups and received by gavage one of the doses $(100,200,400 \mathrm{mg} / \mathrm{kg})$ of EV, DZP $(10 \mathrm{mg} / \mathrm{kg}$ ), or vehicle (distilled water with $2 \%$ Tween 80 ). One hour after the treatment, each animal was placed at the distal end of the enclosed arm of the ETM facing the intersection of the arms. The time taken by the rat to leave this arm with the four paws was recorded (baseline latency). The same measurement was repeated in two subsequent trials (avoidance 1 and 2) at 30-s intervals, during which animals were placed in a Plexiglas cage to which they had been previously habituated. Following avoidance training (30 s), rats were placed at the end of the right open arm of the maze and the latency to leave this arm with the four paws was recorded for 3 consecutive times (escape 1, 2 and 3) with 30-s intertrial intervals.

Chronic study. After arrival in the laboratory, the animals were randomly allocated to different treatment groups and treated for 21 consecutive days with EV (50, 100, $200 \mathrm{mg} /$ $\mathrm{kg})$, DZP $(10 \mathrm{mg} / \mathrm{kg})$, or vehicle. On the 20th day of treatment, pre-exposure to one of the open arms of the maze was performed. The experimental sessions took place on the following day as described for the acute study.

For both the acute and chronic experiments, immediately after being tested in the ETM, each animal was placed in the open field for $5 \mathrm{~min}$ for the evaluation of locomotor activity. During this time, the total number of lines crossed and the frequency of rearings were measured.

\section{Experiment 2 - forced swim test}

Acute study. Experiments were carried out according to the method of Porsolt and co-workers (13). One day before the tests, each animal was placed individually in a plastic cylinder and allowed to swim for 15 min (pretest). After the pretest, rats were removed and dried in a separate cage before returning to their home cages. On the next day, they were submitted to a 5-min test session, $1 \mathrm{~h}$ after treatment (EM and EV: 100,200 , and $400 \mathrm{mg} / \mathrm{kg}$, imipramine: 20 $\mathrm{mg} / \mathrm{kg}$, or vehicle) during which time they continued to swim (i.e., making deliberate movements around the cylinder at a horizontal level across the top of the water), to climb (making intense movements with the four limbs, with the two forepaws either breaking the surface of the water or directed against the walls of the cylinder), and the time spent in immobility (floating, except for small limb movements necessary to keep the head above the water) were recorded. Immediately before the FST session each rat was submitted to the open field for $5 \mathrm{~min}$.

Chronic study. After arrival in the laboratory, animals were allocated randomly to different treatment groups and treated with drugs (EM and EV: 50, 100, and $200 \mathrm{mg} / \mathrm{kg}$, imipramine: $20 \mathrm{mg} / \mathrm{kg}$ ) and vehicle for 21 consecutive days. On the 20th day, the pretest was performed. Twenty- four hours later, the animals were tested in the open field and submitted to the FST as described above.

\section{Statistical analysis}

Split-plot analysis of variance (ANOVA) was used to analyze avoidance and escape measurements, with treatment as the independent factor and trials as the dependent factor. In case of a significant effect of treatment or of treatment versus trial interaction, data were analyzed by one-way ANOVA followed by the Duncan post hoc test. Behavioral data regarding the open field and FST were submitted to one-way ANOVA followed by the Duncan post hoc test. In all cases, a value of $\mathrm{P} \leq 0.05$ was considered significant. 


\section{Results}

\section{Experiment 1 - elevated T-maze}

Acute ETM study. Both EV and DZP decreased ETM avoidance latencies (Figure 1A). Split-plot ANOVA showed a significant effect of treatment $(\mathrm{F}(4,55)=6.38 ; \mathrm{P}<$ $0.01)$, of trials $(\mathrm{F}(2,110)=26.75 ; \mathrm{P}<0.01)$, and of treatment $v s$ trial interaction $(\mathrm{F}(8,110)$ $=2.93 ; \mathrm{P}<0.01)$. One-way ANOVA showed a significant difference among treatments in avoidance $1(\mathrm{~F}(4,55)=7.49 ; \mathrm{P}<0.01)$ and in avoidance $2(\mathrm{~F}(4,55)=3.41 ; \mathrm{P}<0.05)$. The Duncan post hoc test showed revealed significant differences between the control group and the groups treated with 200 and $400 \mathrm{mg} / \mathrm{kg}$ of EV and DZP in avoidance 1, as well as the group treated with $400 \mathrm{mg} / \mathrm{kg}$ of EV and DZP in avoidance $2(\mathrm{P}<0.05)$.

Unlike that observed with the avoidance measurements, however, no significant effects were detected regarding the measurements of escape from the open arms of the ETM (Figure 1B).

Chronic ETM study. Similar to the acute study, EV and DZP also decreased avoidance latencies after repeated treatment (Figure 2A). Split-plot ANOVA showed a significant effect of treatment $(\mathrm{F}(4,54)=2.61$; $\mathrm{P}<0.05)$ and of trials $(\mathrm{F}(2,108)=23.41$; $\mathrm{P}<0.01$ ), but not a significant effect of treatment versus trial interaction. One-way ANOVA showed a significant difference between treatments in avoidance $1(\mathrm{~F}(4,54)$ $=3.20 ; \mathrm{P}<0.05)$. The Duncan post hoc test showed significant differences between the groups treated with 50 and $200 \mathrm{mg} / \mathrm{kg}$ $\mathrm{EV}$ and DZP and the control group $(\mathrm{P}<0.05)$.

Again, unlike that observed with the avoidance measurements, no significant effects were detected on measurements of escape from the open arms of the ETM (Figure 2B).

Open field. Locomotor activity measured in the open field was not affected by acute or chronic treatment with EV or with DZP in rats

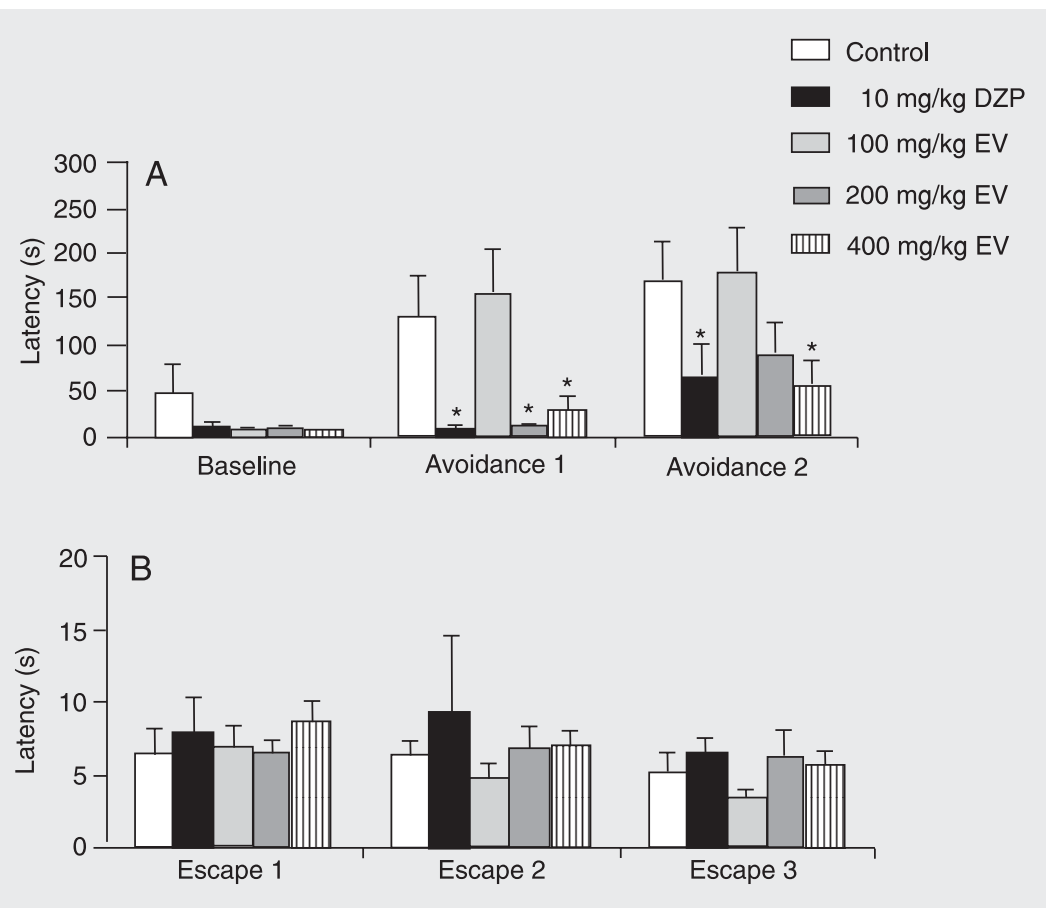

Figure 1. Effect of acute oral administration of a water-alcohol extract of Erythrina velutina (EV) and of diazepam (DZP) on the behavior of rats submitted to the avoidance (panel A) and escape (panel B) tasks of the elevated T-maze. Data are reported as means \pm SEM. N $=12$ for all treatment groups. ${ }^{*} \mathrm{P}<0.05$ compared to control (Duncan test).
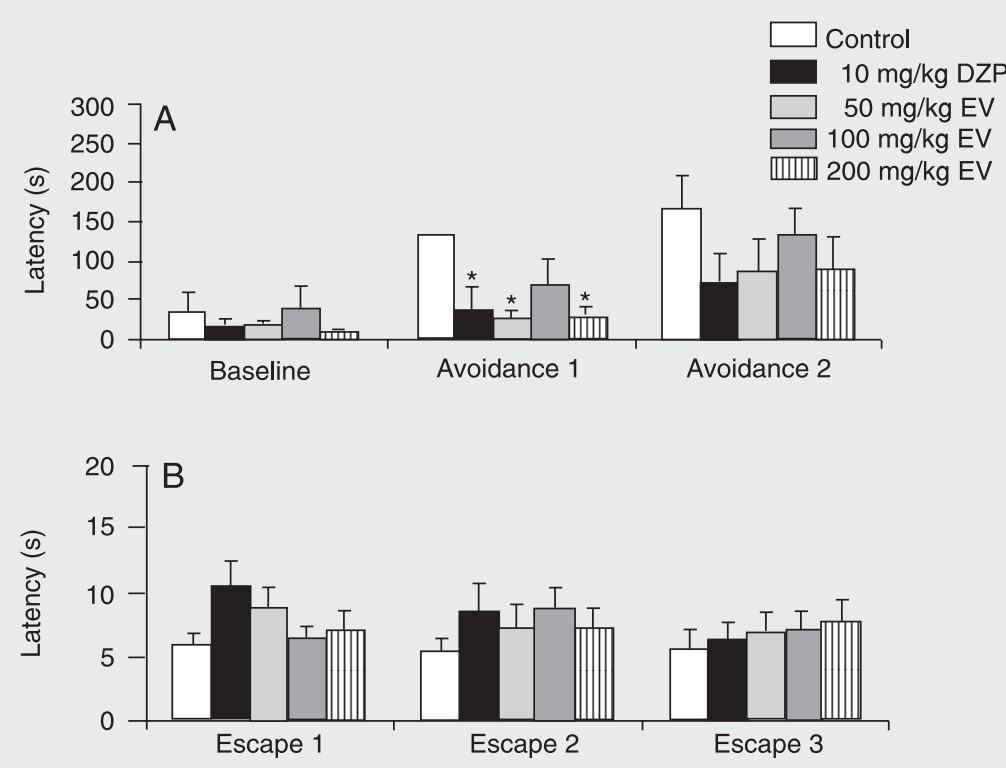

Figure 2. Effect of chronic oral administration of a water-alcohol extract of Erythrina velutina (EV) and of diazepam (DZP) on the behavior of rats submitted to the avoidance (panel A) and escape (panel B) tasks of the elevated T-maze. Data are reported as means \pm SEM. N $=12$ for control, DZP, and 50 and $100 \mathrm{mg} / \mathrm{kg} \mathrm{EV}$ and $\mathrm{N}=11$ for $200 \mathrm{mg} / \mathrm{kg} \mathrm{EV}$. ${ }^{*} \mathrm{P}<0.05$ compared to control (Duncan test). 
previously exposed to the ETM (Table 1).

\section{Experiment 2 - forced swim test}

Acute FST study. No significant differences were detected regarding the time spent

Table 1. Effect of acute and chronic treatment with a water-alcohol extract of Erythrina velutina and diazepam on the locomotor activity of rats submitted to an open field after exposure to the elevated T-maze test.

\begin{tabular}{lcc}
\hline Group & Crossings & Rearings \\
\hline $\begin{array}{l}\text { Acute treatment } \\
\text { Vehicle }\end{array}$ & $45 \pm 6$ & $18 \pm 5$ \\
$100 \mathrm{mg} / \mathrm{kg} \mathrm{EV}$ & $39 \pm 3$ & $14 \pm 2$ \\
$200 \mathrm{mg} / \mathrm{kg} \mathrm{EV}$ & $54 \pm 6$ & $19 \pm 2$ \\
$400 \mathrm{mg} / \mathrm{kg} \mathrm{EV}$ & $58 \pm 6$ & $19 \pm 3$ \\
$10 \mathrm{mg} / \mathrm{kg} \mathrm{DZP}$ & $59 \pm 7$ & $20 \pm 4$ \\
& & \\
Chronic treatment & & \\
Vehicle & $47 \pm 4$ & $15 \pm 2$ \\
$50 \mathrm{mg} / \mathrm{kg} \mathrm{EV}$ & $48 \pm 5$ & $18 \pm 4$ \\
$100 \mathrm{mg} / \mathrm{kg} \mathrm{EV}$ & $52 \pm 5$ & $16 \pm 2$ \\
$200 \mathrm{mg} / \mathrm{kg} \mathrm{EV}$ & $47 \pm 4$ & $16 \pm 4$ \\
$10 \mathrm{mg} / \mathrm{kg} \mathrm{DZP}$ & $43 \pm 6$ & $16 \pm 4$ \\
& & \\
\end{tabular}

Data are reported as means \pm SEM. $\mathrm{N}=12$ for all treatment groups. $\mathrm{EV}=$ Erythrina velutina; DZP = diazepam. One-way ANOVA showed that locomotor activity was not affected by acute or chronic treatment.

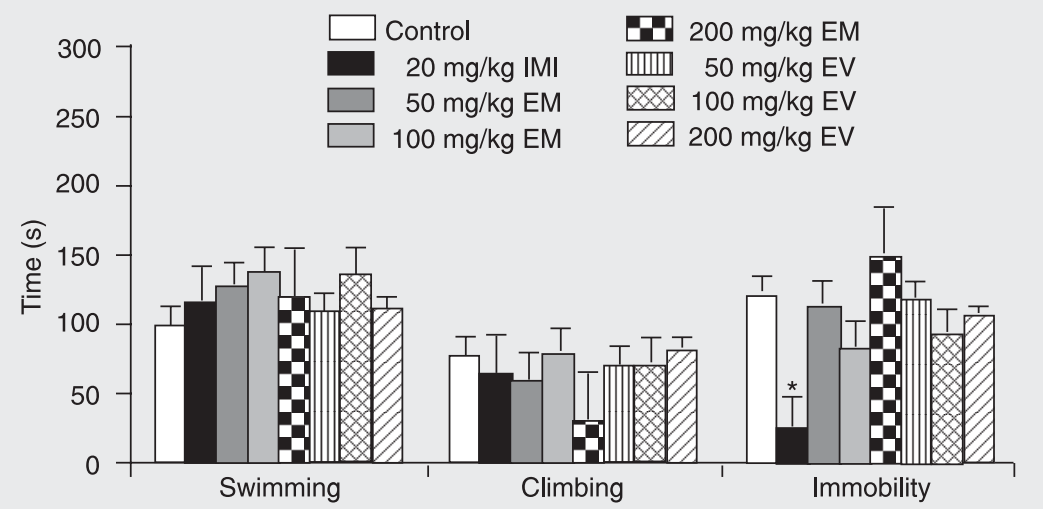

Figure 3. Effect of chronic oral administration of two water-alcohol extracts of Erythrina mulungu (EM), E. velutina (EV) and imipramine (IMI) on the behavior of rats submitted to the forced swim test. Data are reported as means \pm SEM. $\mathrm{N}=10$ for all treatment groups. ${ }^{*} \mathrm{P}<$ 0.05 compared to control (Duncan test). climbing or swimming or in the immobility parameter after acute treatment (data not shown).

Chronic FST study. With repeated treatment, however, imipramine significantly decreased time spent in immobility (one way ANOVA: $\mathrm{F}(7,71)=3.00 ; \mathrm{P}<0.01$; Duncan: $\mathrm{P}<0.05$, with respect to the control group. See Figure 3). Nevertheless, no significant differences between treatments were detected with respect to the other measurements performed in the model.

Open field. Again, locomotor activity measured in the open field was not affected by acute or chronic treatment with EV and EM or with imipramine in rats exposed to the FST (Table 2).

\section{Discussion}

The data presented here show that both acute and chronic oral treatment with a water-alcohol EV extract had anxiolytic effects on the inhibitory avoidance task in the ETM, and that these effects were similar to those obtained with the reference drug DZP. Since no significant effects were observed with any of the acute or chronic EV doses in the open-field test, it is reasonable to assume that these data are not due to motor alterations. It is also interesting to point out that the present results are consistent with those previously observed with EM $(7,8)$ and corroborate previous evidence obtained performed with other animal models of anxiety (11). Pharmacological validation of the ETM model has already shown that, in addition to BZD, two other different classes of anxiolytics - the 5-HT1A agonist buspirone and the 5-HT2 antagonist ritanserin - also selectively impair inhibitory avoidance $(14,15)$ while leaving one-way escape unchanged. Since reported clinical evidence shows that only generalized anxiety is ameliorated by BZD, azaspirones and ritanserinlike drugs, inhibitory avoidance has been related to generalized anxiety. 
Table 2. Effect of acute and chronic treatment with water-alcohol extract of Erythrina velutina, $E$. mulungu or imipramine on the locomotor activity of rats submitted to an open field and subsequently tested in the forced swim test.

\begin{tabular}{lll}
\hline Group & Crossings & Rearings \\
\hline $\begin{array}{l}\text { Acute treatment } \\
\text { Vehicle }\end{array}$ & $58 \pm 6$ & $28 \pm 4$ \\
$100 \mathrm{mg} / \mathrm{kg} \mathrm{EV}$ & $57 \pm 6$ & $25 \pm 3$ \\
$200 \mathrm{mg} / \mathrm{kg} \mathrm{EV}$ & $54 \pm 5$ & $21 \pm 2$ \\
$400 \mathrm{mg} / \mathrm{kg} \mathrm{EV}$ & $52 \pm 5$ & $21 \pm 2$ \\
$100 \mathrm{mg} / \mathrm{kg} \mathrm{EM}$ & $47 \pm 4$ & $18 \pm 2$ \\
$200 \mathrm{mg} / \mathrm{kg} \mathrm{EM}$ & $41 \pm 2$ & $19 \pm 2$ \\
$400 \mathrm{mg} / \mathrm{kg} \mathrm{EM}$ & $37 \pm 4$ & $15 \pm 3$ \\
$20 \mathrm{mg} / \mathrm{kg} \mathrm{IMI}$ & $42 \pm 3$ & $17 \pm 1$ \\
Chronic treatment & & \\
Vehicle & $50 \pm 4$ & $21 \pm 3$ \\
$50 \mathrm{mg} / \mathrm{kg} \mathrm{EV}$ & $49 \pm 5$ & $18 \pm 3$ \\
$100 \mathrm{mg} / \mathrm{kg} \mathrm{EV}$ & $52 \pm 7$ & $24 \pm 3$ \\
$200 \mathrm{mg} / \mathrm{kg} \mathrm{EV}$ & $53 \pm 2$ & $25 \pm 2$ \\
$50 \mathrm{mg} / \mathrm{kg} \mathrm{EM}$ & $51 \pm 3$ & $22 \pm 2$ \\
$100 \mathrm{mg} / \mathrm{kg} \mathrm{EM}$ & $60 \pm 8$ & $26 \pm 4$ \\
$200 \mathrm{mg} / \mathrm{kg} \mathrm{EM}$ & $56 \pm 6$ & $26 \pm 4$ \\
$20 \mathrm{mg} / \mathrm{kg} \mathrm{IMI}$ & $38 \pm 5$ & $19 \pm 2$ \\
\hline
\end{tabular}

Data are reported as means \pm SEM. $N=12$ for control and the three lowest doses of EV and $\mathrm{N}=$ 11 for $200 \mathrm{mg} / \mathrm{kg} \mathrm{EV}$. EV = Erythrina velutina; IMI = imipramine; EM = Erythrina mulungu. One-way ANOVA showed that locomotor activity was not affected by acute or chronic treatment.

On the other hand, in contrast to that reported for EM $(7,8)$, ETM one-way escape was not altered by treatment with EV. In a study by Onusic et al. (8), chronic treatment with EM significantly increased escape from the open arms of the maze, an effect similar to those observed with the tricyclic agent imipramine and with the 5-HT reuptake inhibitor fluoxetine (10), both drugs used in clinical settings to treat panic disorder.

The different behavioral profiles of EV and EM in the ETM are not understood. It is possible, however, that this difference might be related to the multiple chemical constituents present in extracts of both species of Erythrina. Chemical fractionation of the stem bark of EV shows the presence of the isoflavonoid phaseollidin (16), which had been isolated from other species of Erythrina (17-19), but not from EV. Unfortunately, there are no data in the literature concerning the chemical constituents of EM. Thus, further evidence is necessary to determine if the different behavioral effects observed in ETM one-way escape with EV and EM are due to their possibly different chemical components.

In the FST, as expected, chronic treatment with imipramine significantly decreased time spent by the animals in immobility. On the other hand, no significant effects were obtained with the extracts of EV or EM. These results suggest the absence of an antidepressant effect of both plants. Although nonsignificant, there seems to be a tendency to motor impairment after acute administration of the highest dose of EM (400 mg/kg). Nevertheless, a possible sedative action is unlikely to account for the negative results obtained with EM in the FST. A true sedative activity would interfere with the time spent climbing or swimming, decreasing these two parameters, while possibly at the same time increasing time spent in immobility. Furthermore, chronic treatment with EM showed no tendency to motor impairment and yet no significant alterations in the main FST parameters were detected. Thus, the panicolytic profile of EM, observed in the study performed by Onusic and co-workers (8), seems to be independent of a possible antidepressant action, in contrast to what was previously hypothesized. Since it has been suggested that the alkaloids present in some species of Erythrina may alter GABAergic neurotransmission (5), it may be possible that the panicolytic action of EM is similar to that of some potent BZD, such as alprazolam.

On the basis of these considerations, the present results suggest that $\mathrm{EV}$ has anxiolyticlike effects on a specific subset of defensive behaviors, particularly one that has been related in clinical terms to generalized anxiety. These observations support the popular use of extracts of the plant as tranquilizing agents. 


\section{Acknowledgments}

We are grateful to Paulo C. Castrechigni for technical assistance.

\section{References}

1. Vasconcelos SMM, Oliveira GR, Carvalho MM et al. (2003). Antinociceptive activities of the hydroalcoholic extract from Erythrina velutina and Erythrina mulungu in mice. Biological and Pharmaceutical Bulletin, 26: 946-949.

2. Neill DA (1988). Experimental studies on species relationships in Erythrina (Leguminosae: Papilionoideae). Annals of the Missouri Botanical Garden, 75: 886-969.

3. McKee TC, Bokesch HR, McCormick JL et al. (1997). Isolation and characterization of new anti-HIV and cytotoxic leads from plants, marine, and microbial organisms. Journal of Natural Products, 60: 431-438.

4. Garcia-Mateos R, Soto-Hernandez M \& Kelly D (1981). Alkaloids from six Erythrina species endemic to Mexico. Biochemical Systematics and Ecology, 26: 545-551.

5. Garin-Aguilar ME, Luna JE, Soto-Hernandes M et al. (2000). Effect of crude extracts of Erythrina americana Mill. on aggressive behavior in rats. Journal of Ethnopharmacology, 69: 189-196.

6. Hargreaves RT, Johnson RD, Millington DS et al. (1974). Alkaloids of American species of Erythrina. Lloydia, 37: 569-580.

7. Onusic GM, Nogueira RL, Pereira AMS et al. (2002). Effects of acute treatment with a water-alcohol extract of Erythrina mulungu on anxiety-related responses in rats. Brazilian Journal of Medical and Biological Research, 35: 473-477.

8. Onusic GM, Nogueira RL, Pereira AMS et al. (2003). Effects of chronic treatment with a water-alcohol extract from Erythrina mulungu on anxiety-related responses in rats. Biological and Pharmaceutical Bulletin, 26: 1538-1542.

9. Teixeira RC, Zangrossi H \& Graeff FG (2000). Behavioral effects of acute and chronic imipramine in the elevated T-maze model of anxiety. Pharmacology, Biochemistry, and Behavior, 65: 571-576.

10. Poltronieri SC, Zangrossi Jr H \& Viana MB (2003). Antipanic-like effect of serotonin reuptake inhibitors in the elevated T-maze. Behavioural Brain Research, 147: 185-192.

11. Vasconcelos SM, Macedo DS, de Melo CT et al. (2004). Centra activity of hydroalcoholic extracts from Erythrina velutina and Erythrina mulungu in mice. Journal of Pharmacy and Pharmacology, 56: 389-393.

12. Dantas MC, De Oliveira FS, Bandeira SM et al. (2004). Centra nervous system effects of the crude extract of Erythrina velutina on rodents. Journal of Ethnopharmacology, 94: 129-133.

13. Porsolt RD, Bertin A \& Jalfre M (1977). Behavioral despair in mice: a primary screening test for antidepressants. Archives Internationales de Pharmacodynamie et de Therapie, 229: 327-336.

14. Viana MB, Tomaz C \& Graeff FG (1994). The elevated T-maze: a new animal model of anxiety and memory. Pharmacology, Biochemistry, and Behavior, 49: 549-554.

15. Graeff FG, Viana MB \& Tomaz C (1993). The elevated T-maze, a new experimental model of anxiety and memory: effect of diazepam. Brazilian Journal of Medical and Biological Research, 26: 67-70.

16. Rabelo LA, Agra MF, da-Cunha EVL et al. (2001). Homohesperetin and phaseollidin from Erythrina velutina. Biochemical Systematics and Ecology, 29: 543-544.

17. Dagne E, Gunatilaka AAL, Kingston DGl et al. (1993). Two bioactive pterocarpans from Erythrina burana. Journal of Natural Products, 56: 1831-1834.

18. Nkengfack AE, Vouffo TW, Fomum ZT et al. (1994). Prenylated isoflavanone from the roots of Erythrina sigmoidea. Phytochemistry, 36: 1047-1051.

19. Yenesew A, Midiwo JO, Guchu SM et al. (2002). Three isoflav-3enes and a 2-arylbenzofuran from the root bark of Erythrina burttii. Phytochemistry, 59: 337-341. 